\title{
Integrated EDM and 4D BIM-Based Decision Support System for Construction Projects Control
}

\author{
Hassan Mohamed Ayman ${ }^{1, *}$, Sameh Youssef Mahfouz ${ }^{2}$ and Ahmed Alhady ${ }^{3}$ \\ 1 Faculty of Engineering Sciences and Art, Department of Architecture, Misr International University (MIU), \\ Km 28 Misr-Ismailia Road, Qalubia 13621, Egypt \\ 2 Construction and Building Engineering Department, College of Engineering and Technology, Arab Academy \\ for Science, Technology and Maritime Transport (AASTMT), B 2401 Smart Village, Giza 12577, Egypt; \\ symahfouz@aast.edu \\ 3 Civil Department, Faculty of Engineering, British University in Egypt (BUE), Suez Desert Road El Sherouk \\ City, Cairo 11837, Egypt; Ahmed.Alhady@bue.edu.eg \\ * Correspondence: hassan.ayman@miuegypt.edu.eg
}

check for updates

Citation: Ayman, H.M.; Mahfouz, S.Y.; Alhady, A. Integrated EDM and 4D BIM-Based Decision Support System for Construction Projects Control. Buildings 2022, 12, 315. https://doi.org/10.3390/ buildings12030315

Academic Editor: Junbok Lee

Received: 19 January 2022 Accepted: 25 February 2022 Published: 7 March 2022

Publisher's Note: MDPI stays neutral with regard to jurisdictional claims in published maps and institutional affiliations.

Copyright: (C) 2022 by the authors. Licensee MDPI, Basel, Switzerland. This article is an open access article distributed under the terms and conditions of the Creative Commons Attribution (CC BY) license (https:// creativecommons.org/licenses/by/ $4.0 /)$.

\begin{abstract}
Project schedule monitoring and controlling are critical challenges of construction project management that are not adequately implemented, likely due to the predominance of earned value management and the lack of utilizing technology, such as BIM tools. Unlike earned value, earned duration management (EDM) was developed, which includes several indices to track schedule progress and measure the performance of a schedule. The goal of this research was to establish a decision support system to track and monitor construction project activities during construction, with better performance and accuracy. A survey was conducted and distributed among ten site engineers, selected from different construction sites. The survey asked the site engineers about the possible durations of certain activities; based on their answers, the authors started the proposed system. In this study, we aimed to develop a decision support system (DSS), which combines BIM with EDM to help calculate probabilistic total project duration, visually detecting critical activities, monitoring visually risky activities subjected to delay and visually categorizing the accuracy of estimated duration for delayed activities.
\end{abstract}

Keywords: earned duration management; schedule management; building; information modeling; performance measurement; probabilities

\section{Introduction}

Construction projects that are behind schedule and over-budget are challenges that take place internationally. It is rare to find a construction project that has been completed in the originally estimated amount of time and/or within the estimated costs [1-3]. This is because building projects are subject to a variety of circumstances that have major (positive or negative) influences on their schedules and budgets.

On the other hand, project monitoring and control is the process of examining the implementation of the project plan. During the execution phase, the project control process involves limiting the deviations from the project plan, evaluating the project's performance, comparing it to the set planning, analyzing variances, and executing necessary corrective actions [4]. This process eventually grows into cost/schedule control system standards [5]; in the late 1970s, the earned value management system achieved its pinnacle [6].

Earned value management is defined as "a management approach for merging scope, schedule, and resources for realistically monitoring progress of a project" by the Project Management Body of Knowledge (PMBOK) guide [7]. It has been used by a variety of organizations; Lipke [8] and Anbari [9] were the pioneer researchers who identified EVM in some executive cases. 
During the evaluation of construction projects, earned value management (EVM) is extensively used to focus on potential future deviations. The use of EVM helps project managers and owners track and monitor the project under consideration [9]. Moreover, the duration needed to have the project finished and the total cost at project completion can be predicted. However, the project manager may experience low performance or things may go wrong at the beginning of the project. In such cases, the project's performance during the coming assessment period will not be consistent and comparable to previous periods [10].

Earned schedule, on the other hand, was shown by Vandevoorde and Vanhoucke [11] to produce more accurate project duration predictions than any other approach currently available. Earned schedule (ES) is a powerful strategy that assists the executive, program director, and project manager in more effectively managing projects, programs, and portfolios. ES allows EVM performance measures to be converted to time or duration measurements. This improves project schedule performance assessment, forecasts the project's completion time, and supplements the project manager's understanding of the project's completion time prediction.

The fundamental disadvantage of ES is that it calculates duration using EV as a reference, which means that it is still cost-based [12]. To overcome this, earned duration management (EDM) was developed by creating timeframe performance measures.

Building information modeling (BIM) is a rising concept, with a limited pledge to modify, from top to bottom, the classic practices of the engineering sector. BIM can be defined as a working methodology, which aims to enhance how information is made, managed, transferred, and visualized throughout a building's whole life cycle. It "purses" to improve communication between all sectors and persons who are involved in the project by locating the information in the center.

There is an increasing need for developed construction systems and models that can monitor construction project performances visually and more precisely. A few ways to measure a project's duration/schedule performance have been proposed, including EV. The performance measurement baseline (PMB) and a project employing EVM metrics focus on most, if not on all, of these measurements. Anbari, F. T. [9], as cited in Vandevoorde and Vanhoucke [11], provided graphical tools, extensions, and applications of EVM to enhance the use and effectiveness of this important project control method. Lipke [8], as cited in Vandevoorde and Vanhoucke [11], presented the concept of an earned schedule (ES), with its accompanying computation methods for schedule variance (SV) and the schedule performance index (SPI). Then, the computed values from the ES methods were compared numerically and graphically to the values computed using the EVM formulas. The literature shows few research studies on how BIM can be exploited as a project control tool using the power of 3D and 4D simulation of a construction project. Bejarano [13] showed that combining Revit software and the EVM technique could be a valuable tool used to support a project's temporal and financial visualization. This combination is useful in analyzing the project performance and affords the possibility of making quick decisions and timely adjustments. By surveying the literature, and to the best of our knowledge, the research gap we found and address in this research surrounds the fact that there is no decision support system (DSS) that integrates BIM along with earned duration management (EDM) to visually monitor construction projects.

The objectives and major contributions of this study are to:

1. Propose a decision support system that visually detects delays of construction projects and controls the whole performance through EDM matrices.

2. Increase the ability to track the performance of a construction project visually, which could be useful information for all parties in the construction management field.

3. Help consultants decide whether a contractor is on the right track to meet the contract duration or not. Decide when to interfere with the construction process if the performance is not satisfying. 
4. Assist owners so that they are sure that their projects are on the right track, and to track the performance of the project without getting too deeply into technical issues.

The remainder of this work is divided into the following sections. The following section presents a literature review of the most common project control and the evolution of the fourth dimension in building information modeling. Then we discuss the development of a decision support system using EDM metrics and BIM tools, showing the results generated after applying the developed system on a real case study. Finally, we present our conclusions.

\section{Brief Literature Review}

In the following subsections, a literature review on project control methods is introduced. Moreover, a literature survey presented on the fourth dimension of building information modeling (BIM), and how it can be utilized in the construction industry, is presented.

\subsection{Project Control Techniques}

Earned value management (EVM) is a project management tool that aids in project control. EVM is capable of showing the project status as well as calculating current deviations [14]. However, it fails in the latter part of the schedule for projects that are behind schedule, where the SPI and SV approaches end at values of 1.00 and 0.00 , respectively. This results in a lack of confidence in the applicability of the EVM to schedule management. Thus, EVM has been used almost exclusively to manage costs for many years. Vandevoorde and Vanhoucke [11] created forecasting models based on project cost and time performance possibilities.

Anbari [9] presented a cost-based index for predicting future performance. Dillibabu and Krishnaiah [15] introduced a software project's expected cost performance in terms of effort expended using an effective strategy and achieving a more reasonable outcome. EVM uses the previous performances of construction projects to predict the future performance. Jacob and Kane [16] stated that EVM's most known performance measurements, when applied to each activity separately rather than to a group of activities at once, are actual indications of project performance. Using a simulation that is built on a network, Barraza et al. [17] created a probability-based model for project time and cost prediction. They clarified the relation between past and future achievement by altering the variables of future activity probability distributions based on completed job performance indicators (CPI in EVM model). Salari et al. [18] predicted the future performance of construction projects considering fuzzy time series. The core of EVM by Christensen (1990) could be drawn using graphs; planned value (PV), actual cost $(\mathrm{AC})$, and earned value $(\mathrm{EV})$ are the three main curves on the EVM diagram (EV). The PV curve shows the budgeted cost of planned work, and the PV information can be found in the contractor bid that was initially filed and approved. The AC curve depicts the overall actual cost expended, whereas the EV curve reflects the actual money received for finished work in accordance with planned values. The EV can be used to show how well the project team consumes project resources, and the percent complete (PC) method is one of the simplest ways to measure EV, as shown in (Equation (1)):

$$
\mathrm{EV}=\mathrm{PV} \times \mathrm{PC}
$$

During the implementation phase of a project, the AC and EV curves are dynamically created. Cost-related data are used in the EV analysis to assess project cost and schedule performance. EV analysis utilizes the following variable in (Equation (2)) to evaluate project schedule performance:

$$
\mathrm{SPI}=\frac{\mathrm{EV}}{\mathrm{PV}}
$$

As a useful enhancement of EVM, ES requires no further data gathering and offers important insights into the project schedule and outcome prediction. Its application in 
practice is currently limited as the acquired schedule scale measures the progress of the project in a time dimension [19]. The ES technology introduced by Lipke [20] provides a solution to the discrepancies between SPI and SV. The ES value can be determined graphically by getting the point at which the horizontal dropping of an EV at a given time intersects with the PV curve on the time axis (horizontal coordinates). ES is an influential method used to help all construction parties manage projects, programs, and portfolios more efficiently. It changes the required EVM metrics into time or duration measurements to improve project schedule performance assessment, forecast project completion duration, and generate greater "managerial awareness" of the estimators [21]. Figure 1 shows a diagram illustrating the concept of earned value and earned schedule.

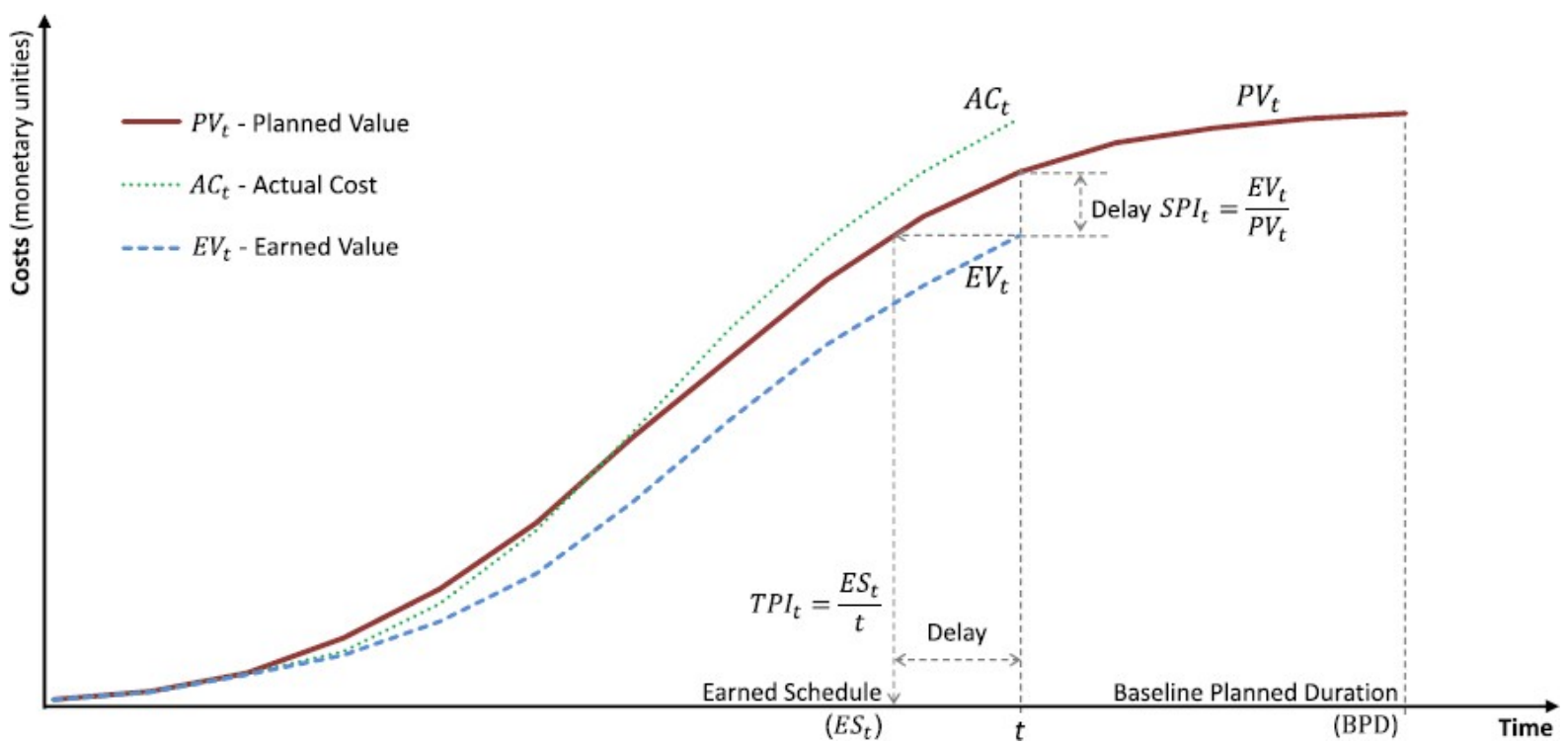

Figure 1. Earned value and earned schedule conceptual diagram. (Reprinted with permission from ref. [22]. Copyright 1983 American Society of Civil Engineers.)

The ES approach, according to the authors, is the finest and most dependable method used to predict project final duration. The authors looked at statistical confidence limitations in order to enhance the estimated completion time.

Vanhoucke [23] built a model that evaluated the efficacy of four primary sensitivity measures in improving project schedule performance dynamically throughout execution. In [24], Vanhoucke proposed two different project tracking approaches to identify project difficulties. Their impact on the quality of control methods to get the project back on track were examined. This was conducted by using a large number of simulations performed on a wide array of fictional project networks created under a controlled design. On a wide set of fake projects that were subjected to Monte Carlo simulations to simulate fictional project progress under uncertainties, bottom-up and top-down project tracking methodologies were both employed together within the corrective measures framework.

Elshaer [10] also examined the impact of activity information sensitivity on the ES method's predicting reliability. To reach this goal, he tested the assertion that the SPI index provided by ES is reliable at greater levels of WBS in typical conditions. Activitybased sensitivity measures were used as activity weighing variables to improve schedule performance by eliminating or mitigating the adverse effects that incorrect warnings could have in noncritical activities. Simulations of a wide array of benchmark projects show that the ES model's forecasting precision can be enhanced using sensitivity information.

Colin and Vanhoucke [25] merged the EVM and ES approaches with various control points based on critical chain/buffer management (CC/BM). They demonstrated how the EVM/ES project control techniques complement the principle of buffers and could improve the project control process when smartly coupled. Some of the limitations of 
classic EVM/ES highlighted in the literature are addressed by these integrated top-down methods.

The new pointers for ES technology perform better than EV. However, using cost data to evaluate project schedule performance causes the information obtained to not always be reliable. Thus, in a recent research paper, the earned duration management (EDM) technique was used to manage the schedule performance [26]. The EDM technique deleted the utilization of cost parameters in the context of the schedule [27]. Figure 2 shows a conceptual chart for earned duration management (EDM).

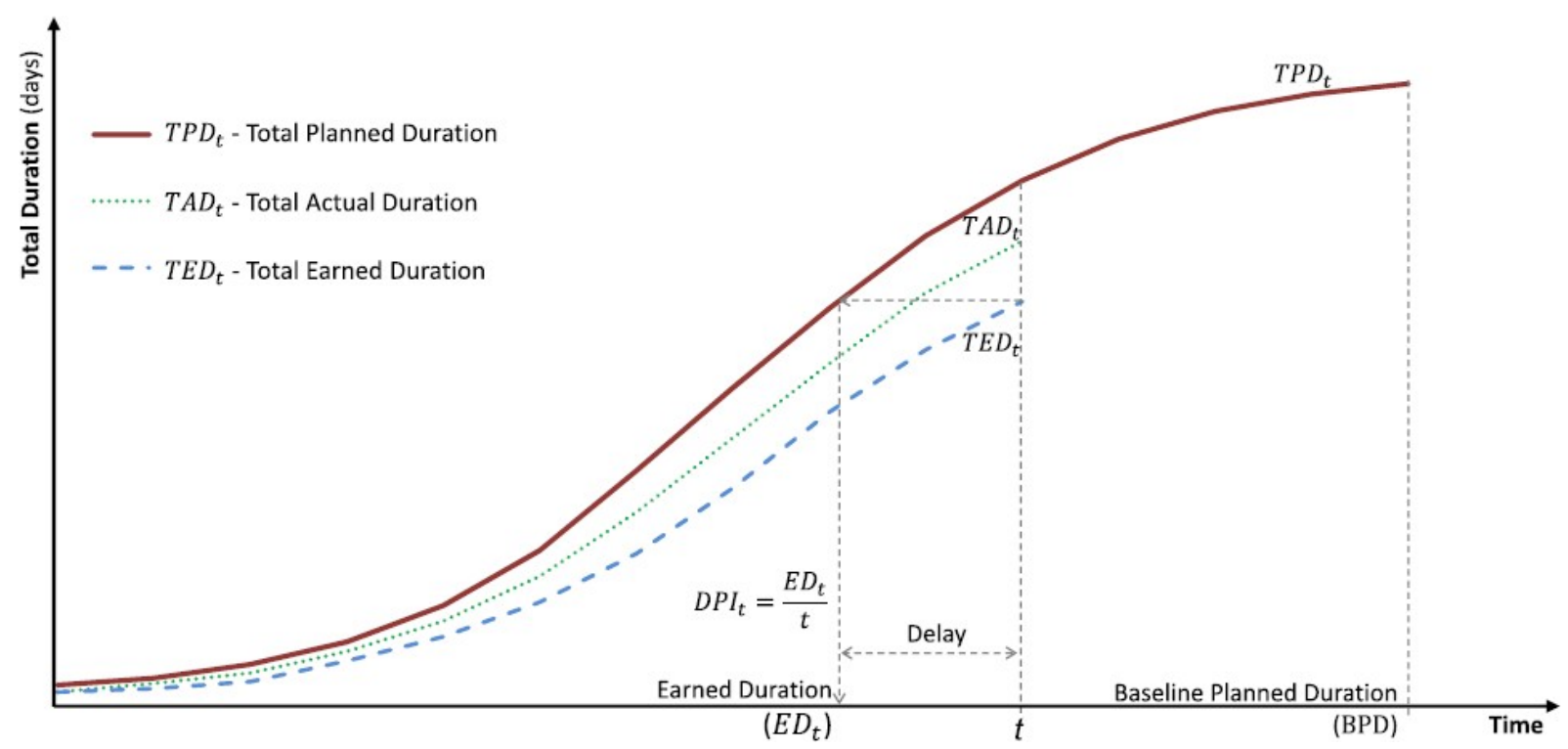

Figure 2. Earned duration management metrics. (Reprinted with permission from ref. [22]. Copyright 1983 American Society of Civil Engineers.)

EDM analysis uses the following parameter in (Equation (3)) to evaluate project schedule performance:

$$
\mathrm{DPI}=\frac{\mathrm{ED}}{\mathrm{AD}}
$$

where DPI stands for duration performance index; DPI demonstrates how effectively the activity progresses toward the finish date. ED is the earned duration corresponding to EV in the earned value system but without using monetary units.

EDM also "proposes" a factor to assist measuring the validity of the originally estimated durations of each activity, which is the duration estimation index (DEI) calculated using Equation (4):

$$
\mathrm{DEI}=\frac{\mathrm{BPD}}{\mathrm{AD}}
$$

where BPD is the baseline planned duration, or, in other words, the originally estimated duration before execution.

\subsection{Fourth Dimension in BIM}

This section focuses the fourth dimension of building information modeling (BIM) as it is the most relevant to our research study. Koo and Fischer [28] explained that adding the fourth dimension (4D) to a three-dimensional (3D) model could be beneficial for building project management. They explained that $4 \mathrm{D}$ planning involves linking the schedule with a 3D model to improve building planning techniques by:

- Visualizing the links between time and space for building activities.

- Constructing schedule analyses to assess its implementation.

- Reducing errors by verifying the plan and strengthening communication among members of the project team. 
BIM is becoming increasingly important in today's construction industry, with significant content provided on the fundamentals and capabilities of 4D BIM [29]. Kummell [30] showed that the application of $4 \mathrm{D}$ in combination with $3 \mathrm{D}$ enhances project planning. It also leads to improved quality of the final product while reduces the waste of resources. Hartmann [31] stated that the 4D model includes the start and end date data for the supply and installation of building. It removes the challenge associated with the traditional scheduling of the construction sequence for the misunderstanding caused by the lack of visualization. The project team could enhance the overall schedule by adding start and end dates to model elements and communicate this to all members of the team, as required, at any moment during the project. Hartman [31] also explained that 4D models expand the value of traditional 3D process along with better scheduling techniques. He explained that the models will improve site planning by enabling the monitoring of "what if" scenarios. They will be helpful in quick decision making and will be valuable by the contractor, design team, and owner.

Arboleda [32] mentioned that $4 \mathrm{D}$ visualizations have been defined as simpler representations of project developments and could be utilized by several project participants with different levels of capabilities and knowledge. Ahmed and Farrell [33] mentioned that one of the $4 \mathrm{D}$ accomplishments is known to increase building plan understanding through visualizations. According to Moon, Dawood, and Kang [34], 4D custom tools now integrate multiple models and timeline data, associating smart objects with resources and link activities with each other. According to Halin, Kubicki, and Boton [35], 4D combines schedule-related information with a 3D model. This allows the user to visualize the process by which a building model will advance and is used to enable construction practitioners to make informed decisions that motivate a reduced time lag.

\section{Research Framework}

In this study, we aimed to develop a decision support system (DSS) that combines BIM with EDM techniques to help in:

1. Calculating probabilistic total project duration.

2. Visually detecting critical activities.

3. Monitoring visually risky activities subjected to delay.

4. Visually categorizing the accuracy of the estimated duration for delayed activities.

Figure 3 shows the research framework followed during this study. The activities involved in any construction project are listed in an Excel spreadsheet model using assigned durations, where each activity is assigned at least three different durations based on the probabilities of occurrence of these durations in construction projects with the same category. To develop the proposed system, the following steps were followed:

- The baseline schedule was created using Primavera software and exported using Excel software to assign the probabilistic durations to the activities. This facilitated getting the critical activities highlighted and the total project duration calculated using Crystal Ball software.

- A 3D model for the project was created using Revit software, linked with the baseline schedule, formed to get the 4D model for the project ready for simulation.

- Going through the phases of the project, updates took place periodically on a fixed basis as stated in the project's contract. Every update showed the change in the critical activities, visually, during simulation of the 4D model.

- The activities that were still in progress with the performance below a certain level or, in other words, the activities that had a duration performance index (DPI) value below a certain factor are highlighted. This acted as a warning tool for all construction parties involved in this project as these activities were risky activities subjected to delay.

- The duration estimation index (DEI) for the finished activities was calculated at each phase. This enabled the user to visually categorize the accuracy of the estimated duration for delayed activities. 
- At each update phase, the actual durations of the finished activities replaced the durations assigned for these activities from the previous phase.

- The durations of the activities that were still in progress and activities that did not started until the cutoff date remained as they were for the simulation to run again using Crystal Ball software.

- At each run for Crystal Ball software, the durations for the remaining activities were determined based on the user choice from the data extracted upon the Crystal Ball simulation. The user could choose the durations needed to meet the contract duration for the project or the durations needed to meet a pre-determined certainty level stated in the contract.

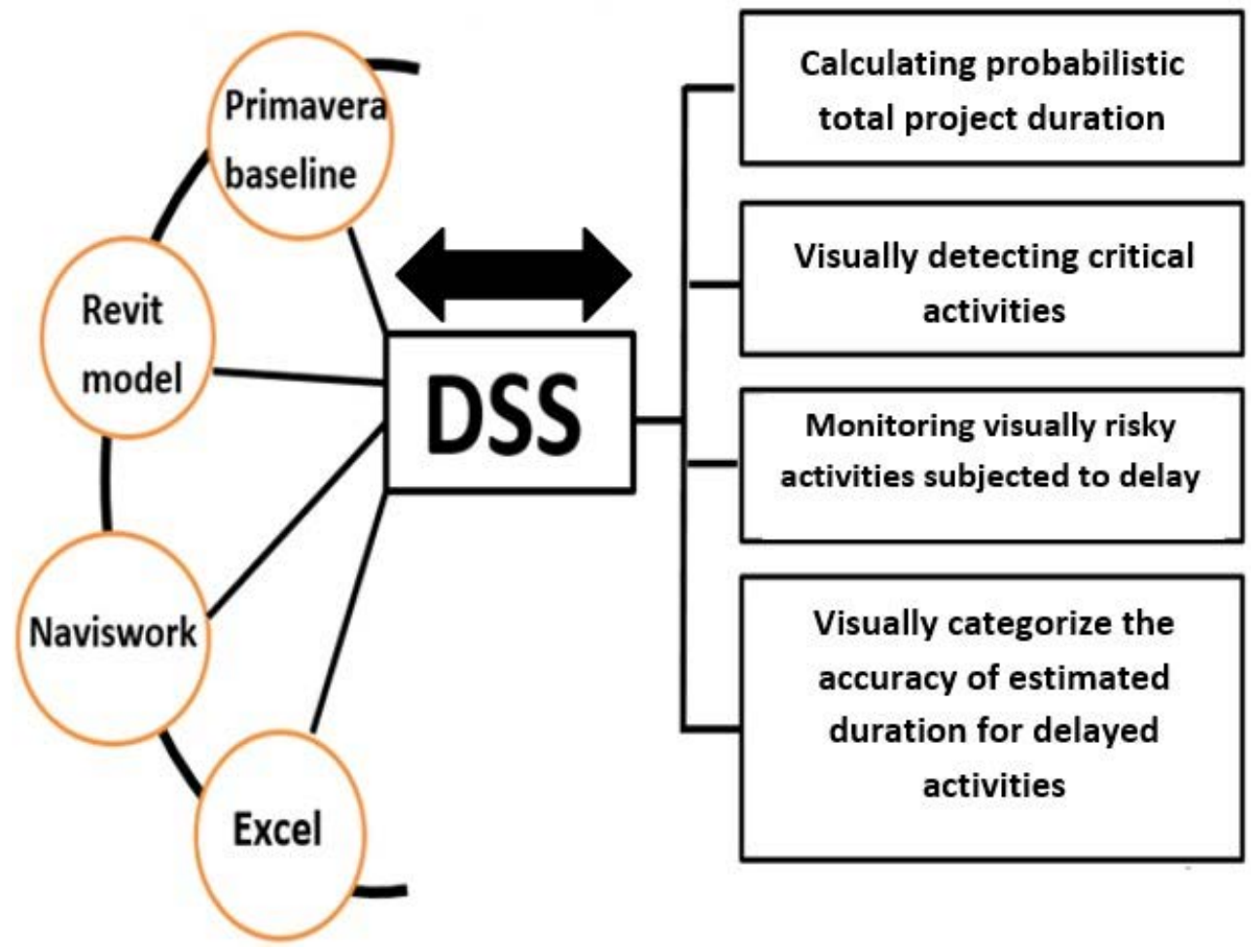

Figure 3. Research framework.

\section{Development of the Decision Support System}

The proposed system functions through three elements:

1. Spreadsheet model.

2. Monte Carlo simulation.

3. Integration between BIM tools and spreadsheet model.

The primavera baseline and the Revit model for a small building were utilized to construct the Navisworks model. Then the proposed system was created upon the Navisworks and the spreadsheet models; the results were generated based on the link between both software. To ensure the effectiveness of the proposed system, it was validated, as will be explained in Section 5.

The spreadsheet model shows the activities that are supposed to be monitored using EDM calculations (DEI, DPI, etc.). It is divided into several sheets, starting with the baseline schedule sheet and continuing with update sheets (first update, second update, etc.). Every sheet shows the activity durations, predecessors, and successors of each activity, the earned duration metrics employed in the system (ED, DEI, and DPI), and the real durations required to meet the contract duration or achieve a target certainty. This is shown in Figure 4.

The durations of the activities were assigned based on previous experiences in similar projects, where each activity had at least three different durations with their probabilities 
of occurrence. Using Crystal Ball software, the durations were simulated based on their probability distributions, where several trials were made with the total project duration forecasted at each trial. Users could select either the durations required to meet the contract duration, or the durations needed to maintain certainty levels agreed upon regardless of the contract duration.

\begin{tabular}{|c|c|c|c|c|c|c|c|c|c|c|c|c|c|c|c|c|c|c|c|c|c|c|c|c|}
\hline \multirow{3}{*}{${ }_{4}^{2}-$} & \multirow{2}{*}{\multicolumn{3}{|c|}{$\begin{array}{c}\text { Contract Duration = } \\
\text { Certainity = }\end{array}$}} & 95 & \multirow{2}{*}{\multicolumn{3}{|c|}{ Predecessors }} & \multirow{2}{*}{\multicolumn{3}{|c|}{ Successors }} & \multirow{2}{*}{\multicolumn{12}{|c|}{ CPM Calculations }} & \multirow{3}{*}{\multicolumn{2}{|c|}{$\begin{array}{l}\text { real duration to meet } \\
\text { certainity } 80 \% \text { - baseline } \\
\text { scenario } 95 \text { days }\end{array}$}} \\
\hline & & & & $80 \%$ & & & & & & & & & & & & & & & & & & & & \\
\hline & ID & \multicolumn{2}{|c|}{ Name } & $\begin{array}{c}\text { Duration } \\
\text { distribution }\end{array}$ & P1 & P2 & P3 & $\$ 1$ & S2 & \$3 & lag & $\mathrm{F} 1$ & F2 & F3 & $\mathrm{T} 1$ & $\mathrm{~T} 2$ & $\mathrm{~T} 3$ & ES & EF & LS & LF & TF & & \\
\hline 5 & 1 & \multicolumn{2}{|c|}{ Excavation \& levelling } & 6 & & & & 2 & & & 0 & 0 & 0 & 0 & 6 & 102 & 102 & 0 & 6 & 0 & 6 & 0 & 7 & \\
\hline 6 & 2 & \multicolumn{2}{|c|}{ PC Footing } & 4 & 1 & & & 3 & & & 0 & 6 & 0 & 0 & 10 & 102 & 102 & 6 & 10 & 6 & 10 & 0 & 4 & \\
\hline 7 & 3 & \multicolumn{2}{|c|}{ RC Footing } & 8 & 2 & & & 4 & & & 0 & 10 & 0 & 0 & 18 & 102 & 102 & 10 & 18 & 10 & 18 & 0 & 8 & \\
\hline 8 & 4 & \multicolumn{2}{|c|}{ Columns GF } & 7 & 3 & & & 5 & & & 0 & 18 & 0 & 0 & 25 & 102 & 102 & 18 & 25 & 18 & 25 & 0 & 7 & \\
\hline 9 & 5 & \multicolumn{2}{|c|}{ Backfilling } & 4 & 4 & & & 6 & & & 0 & 25 & 0 & 0 & 29 & 102 & 102 & 25 & 29 & 25 & 29 & 0 & 4 & \\
\hline 10 & 6 & \multicolumn{2}{|c|}{ S.0.G } & 3 & 5 & & & 7 & & & 0 & 29 & 0 & 0 & 32 & 102 & 102 & 29 & 32 & 29 & 32 & 0 & 4 & \\
\hline 11. & & \multicolumn{2}{|c|}{ Beams \& Slab GF } & 7 & 6 & & & 8 & & & 0 & 32 & 0 & 0 & 39 & 102 & 102 & 32 & 39 & 32 & 39 & 0 & 7 & \\
\hline 12 & 8 & \multicolumn{2}{|c|}{ Columns First } & 7 & 7 & & & 9 & & & 0 & 39 & 0 & 0 & 46 & 102 & 102 & 39 & 46 & 39 & 46 & 0 & 7 & \\
\hline 13. & 9 & \multicolumn{2}{|c|}{ Beams \& Slab First } & 7 & 8 & & & 10 & 17 & & 0 & 46 & 0 & 0 & 53 & 72 & 102 & 46 & 53 & 46 & 53 & 0 & 7 & \\
\hline 14. & & \multicolumn{2}{|c|}{ Columns Second } & 7 & 9 & & & 11 & & & 0 & 53 & 0 & 0 & 60 & 102 & 102 & 53 & 60 & 53 & 60 & 0 & 6 & \\
\hline 15 . & 11 & \multicolumn{2}{|c|}{ Beams \& Slab Second } & 7 & 10 & & & 12 & 19 & & 0 & 60 & 0 & 0 & 67 & 84 & 102 & 60 & 67 & 60 & 67 & 0 & 7 & \\
\hline 16 & & \multicolumn{2}{|c|}{ Columns Third } & 7 & 11 & & & 13 & & & 0 & 67 & 0 & 0 & 74 & 102 & 102 & 67 & 74 & 67 & 74 & 0 & 6 & \\
\hline 17 & 13 & \multicolumn{2}{|c|}{ Beams \& Slab Third } & 7 & 12 & & & 14 & 20 & & 0 & 74 & 0 & 0 & 81 & 90 & $\mid 102$ & 74 & 81 & 74 & 81 & 0 & 7 & \\
\hline & 11 & Baseline & \multicolumn{2}{|c|}{ Data for Baseline Simulation } & \multicolumn{3}{|c|}{ First Update } & \multicolumn{5}{|c|}{ Data for 1st Update Simulation } & \multicolumn{4}{|c|}{ Second update $\mid$} & \multicolumn{3}{|c|}{ | NAVISOWRKS } & \multicolumn{4}{|c|}{ Data 2nd update Simulation } & Third Upda \\
\hline
\end{tabular}

Figure 4. The interface of the spreadsheet model.

A 4D simulated model for the project was created using Navisworks software to be linked with the spreadsheet model The main role of this sheet was to prepare the data in the form to be understood by the Navisworks software; the Navisworks could deal with data extracted from spreadsheet in the form of a CSV file. All activities needing to be visualized according to their DEI and DPI values were linked to this sheet using the "IF conditional" function in Excel.

For example, the activities that had a DEI of less than 0.80 in the first update sheet that needed to be visualized with the yellow color, as shown in the previous sections, were linked to the Navisworks sheet, as shown in Figure 5. All activities having a DEI of less than 0.80 had the word "true"; in other words-all of the activities that needed to be visualized according to their DEI or DPI values, have the value "true".

\begin{tabular}{|c|c|c|c|c|c|c|}
\hline G3 & & $r \quad \vdots$ & $x \vee f_{x}$ & irst Update'!Y5< & .8,"True" & "False") \\
\hline$\triangle$ & A & & B & $E$ & G & $\mathrm{H}$ \\
\hline 1 & \multirow[b]{2}{*}{ ID } & \multirow{2}{*}{\multicolumn{2}{|c|}{ Name }} & Baseline & \multicolumn{2}{|c|}{ First Update } \\
\hline 2 & & & & $\begin{array}{c}\text { (critical or } \\
\text { not) }\end{array}$ & & DPI \\
\hline 3 & 1 & Excav & ation \& levelling & True & False & False \\
\hline 4 & 2 & & PC Footing & True & True & False \\
\hline 5 & 3 & & RC Footing & True & False & False \\
\hline 6 & 4 & & Columns GF & True & False & True \\
\hline 7 & 5 & & Backfilling & True & False & False \\
\hline 8 & 6 & & S.O.G & True & False & False \\
\hline
\end{tabular}

Figure 5. If function used for data preparation. 
The main step was exporting this sheet to a ".csv" format, to be linked to the Navisworks model, through the steps shown in the following figures.

- The first step was to export the spreadsheet containing data to be reviewed using Navisworks into a .csv format, as shown in Figure 6.

- The second step, in the "Data Sources" tab in Navisworks, involved clicking the "Add" button, choosing the option "CSV Import", and choosing the requested file, as shown in Figure 7.

- The third step in the "Edit" menu of the new data source placed the column headings in the same way as the .csv file, as shown in Figure 8.

- The final step in the "Edit" menu of the new data source involved choosing the activities needed to visualize (critical activities, activities with $\mathrm{DEI}<0.80$, and activities with DPI < 0.80). For example, Figure 9 shows that the activities with DPI less than 0.8 in the fourth update scenario were going to appear in different colors during simulation.

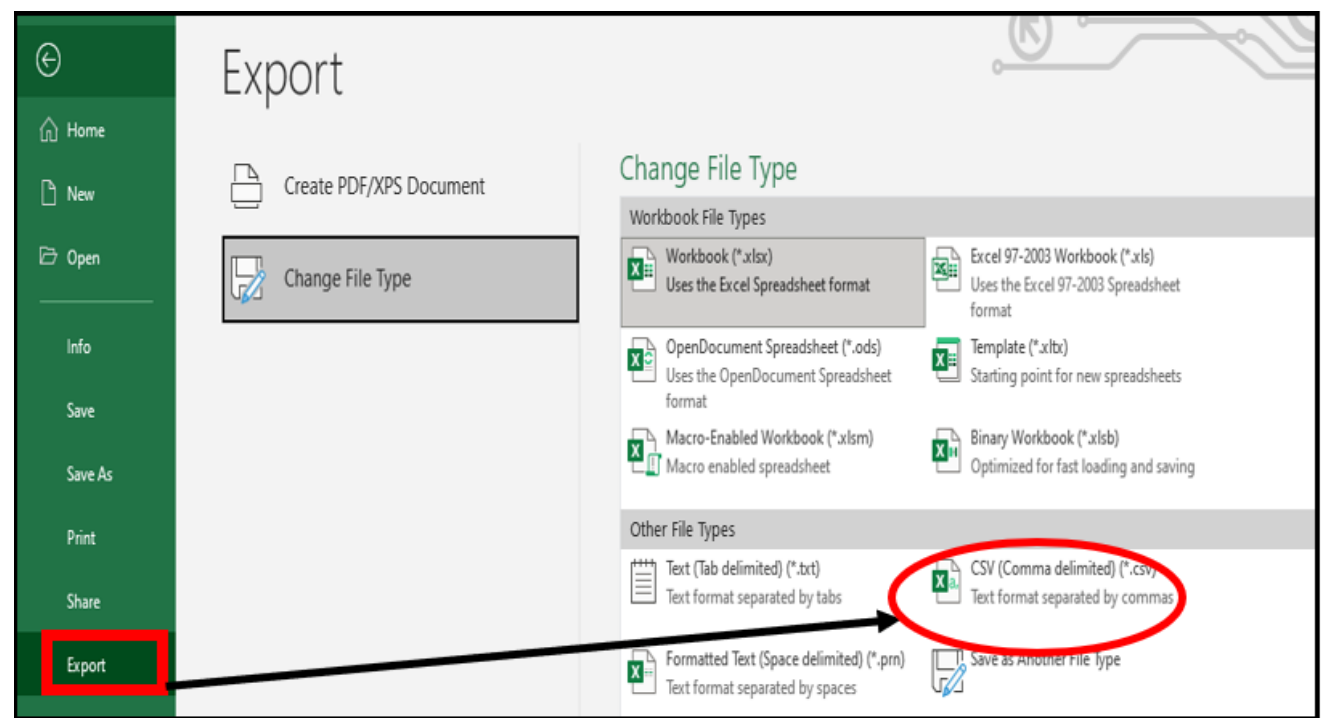

Figure 6. Preparing the .csv file.

TimeLiner

\begin{tabular}{l|l|l|l|}
\hline Tasks & Data Sources & Configure & Simulate
\end{tabular}

Add - EDelete ERefresh -

Name

New Data Source

Source

CSV Import

Figure 7. Importing the .csv file to the Navisworks software. 


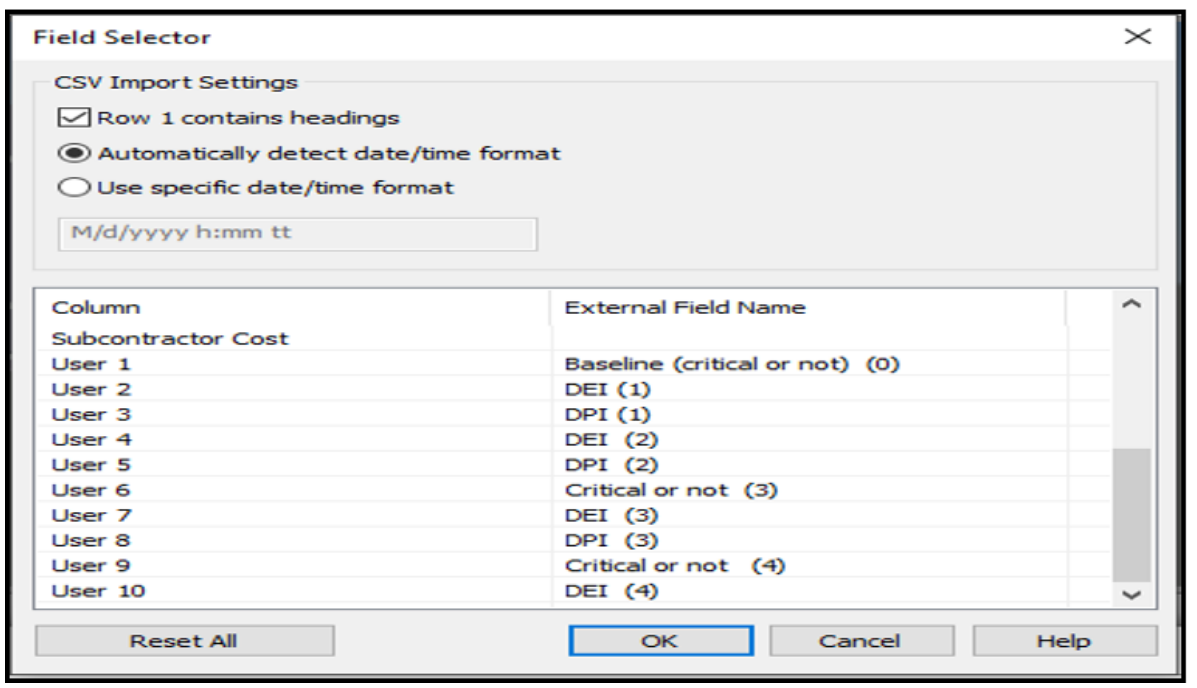

Figure 8. Adjustment of columns headings.

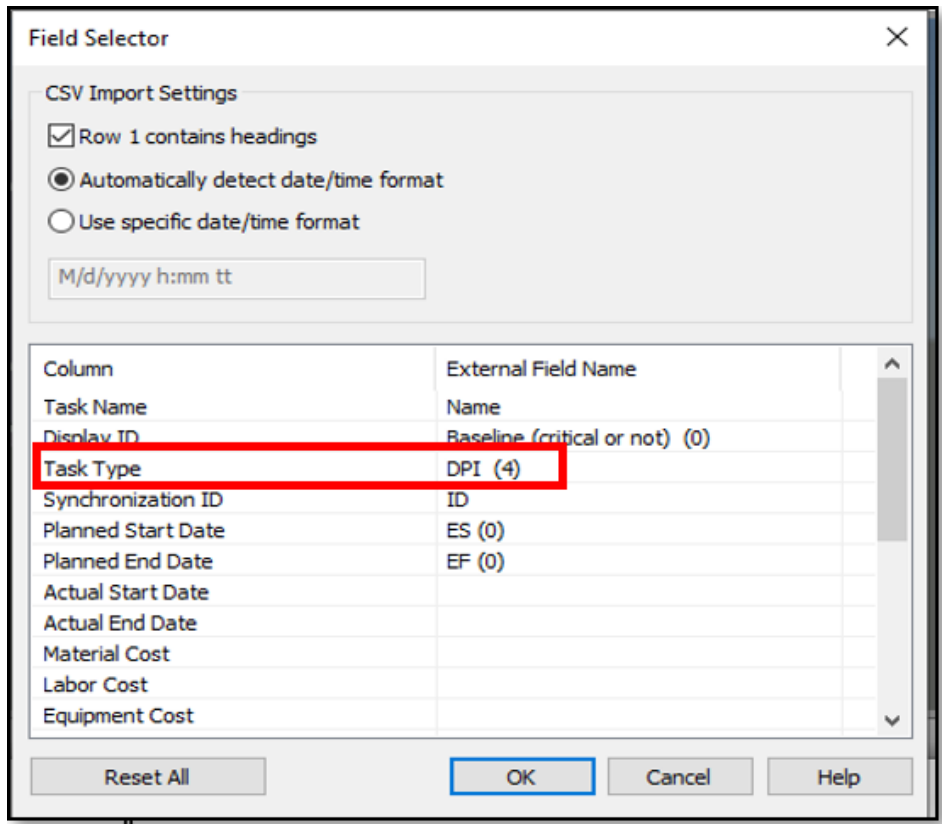

Figure 9. Adjusting the task type.

Activities with DEI and DPI below certain levels and critical activities were highlighted with different colors during the simulation of the project using Navisworks. By this, the construction project parties could monitor and track their projects easily and take decisions to keep their projects on track during the construction process. The application of the developed decision support system is demonstrated using a real-life case. It was used for monitoring and tracking the progress of a residential building project in Egypt. This building was part of a huge residential project, including the construction of all structural elements and the brickwork of the whole building. The developed system proposes two possible solutions at each phase during construction, either to use the durations required to meet contract durations (which is equal to 95 days in our case study) or to use durations required to maintain certainty level at $80 \%$ (based on an agreement between the contractor and the consultant). The simulation for the durations using Crystal Ball software, as shown in Figure 10. Table 1 shows the activities listed in this project showing the predecessor and successor of each activity. 


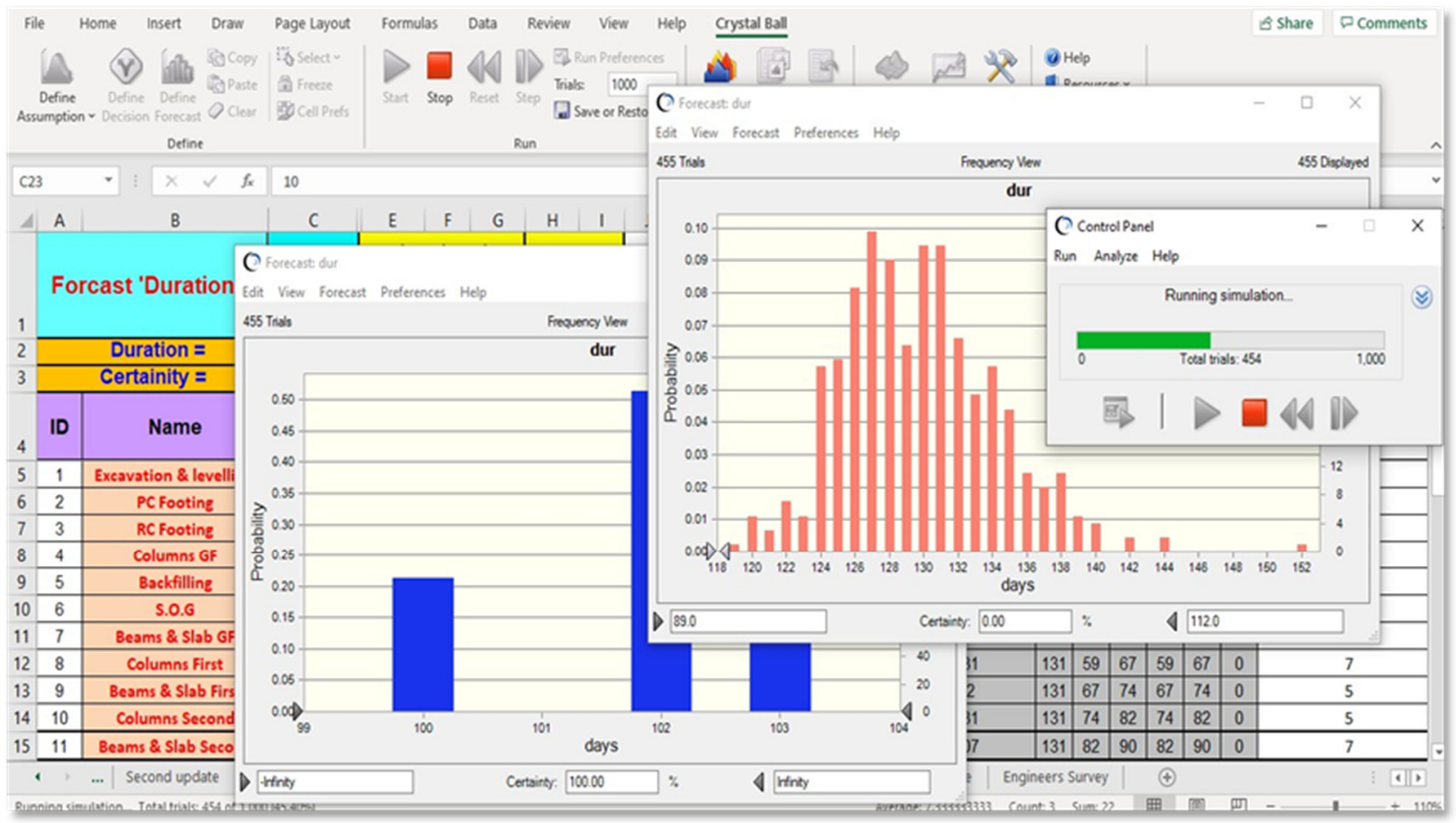

Figure 10. Simulation for activities durations using Crystal Ball software.

Table 1. Activities listed in the case study with the predecessors and successors of each activity.

\begin{tabular}{|c|c|c|c|c|c|c|c|}
\hline \multirow{2}{*}{ ID } & \multirow{2}{*}{ Name } & \multicolumn{3}{|c|}{ Predecessors } & \multicolumn{3}{|c|}{ Successors } \\
\hline & & P1 & $\mathbf{P 2}$ & P3 & S1 & S2 & S3 \\
\hline 1 & Excavation and leveling & & & & 2 & & \\
\hline 2 & PC footing & 1 & & & 3 & & \\
\hline 3 & $\mathrm{RC}$ footing & 2 & & & 4 & & \\
\hline 4 & Columns (ground floor) & 3 & & & 5 & & \\
\hline 5 & Backfilling & 4 & & & 6 & & \\
\hline 6 & Slab on grade & 5 & & & 7 & & \\
\hline 7 & Beams and slab (ground floor) & 6 & & & 8 & & \\
\hline 8 & Columns first floor & 7 & & & 9 & & \\
\hline 9 & Beams and slab first floor & 8 & & & 10 & 17 & \\
\hline 10 & Columns second floor & 9 & & & 11 & & \\
\hline 11 & Beams and slab second floor & 10 & & & 12 & 19 & \\
\hline 12 & Columns third floor & 11 & & & 13 & & \\
\hline 13 & Beams and slab third floor & 12 & & & 14 & 20 & \\
\hline 14 & Columns fourth floor & 13 & & & 15 & & \\
\hline 15 & Beams and slab fourth floor & 14 & & & 16 & 21 & \\
\hline 16 & Columns and parapet roof & 15 & & & & & \\
\hline 17 & Brick works ground floor & 9 & & & 18 & & \\
\hline 18 & Brick works first floor & 17 & & & 19 & & \\
\hline 19 & Brick works second floor & 18 & 11 & & 20 & & \\
\hline 20 & Brick works third floor & 19 & 13 & & 21 & & \\
\hline 21 & Brick works fourth floor & 20 & 15 & & & & \\
\hline
\end{tabular}


A questionnaire was made for ten site engineers who visited different construction sites of similar residential building projects. Every site engineer was asked to give an approximated duration for each activity based on his experience to collect at least three different durations for each activity. The probability of each duration was calculated using Equation (5):

\section{Number of site engineers recommended this duration}

$$
\text { Sample size }
$$

where the sample size equals to ten.

The results for the questionnaire are presented as shown in Figures 11-13:

\begin{tabular}{|c|c|c|c|c|c|c|c|c|c|c|}
\hline & $\begin{array}{c}\text { Columns } \\
\text { Third }\end{array}$ & $\begin{array}{c}\text { Beams \& } \\
\text { Slab } \\
\text { Third }\end{array}$ & $\begin{array}{c}\text { Columns } \\
\text { Fourth }\end{array}$ & $\begin{array}{c}\text { Beams \& } \\
\text { Slab } \\
\text { Fourth }\end{array}$ & $\begin{array}{c}\text { Columns } \\
\& \\
\text { Parapet } \\
\text { Roof }\end{array}$ & $\begin{array}{c}\text { Brick } \\
\text { Works } \\
\text { Ground }\end{array}$ & $\begin{array}{c}\text { Brick } \\
\text { Works } \\
\text { First }\end{array}$ & $\begin{array}{c}\text { Brick } \\
\text { Works } \\
\text { Second }\end{array}$ & $\begin{array}{l}\text { Brick } \\
\text { Works } \\
\text { Third }\end{array}$ & $\begin{array}{l}\text { Brick } \\
\text { Works } \\
\text { Fourth }\end{array}$ \\
\hline Site engineer 1 & 6 & 7 & 5 & 7 & 4 & 8 & 8 & 8 & 8 & 8 \\
\hline Site engineer 2 & 4 & 7 & 5 & 7 & 4 & 8 & 8 & 8 & 8 & 8 \\
\hline Site engineer 3 & 4 & 5 & 4 & 5 & 5 & 7 & 7 & 7 & 7 & 7 \\
\hline Site engineer 4 & 6 & 10 & 5 & 10 & 3 & 8 & 8 & 8 & 8 & 8 \\
\hline Site engineer 5 & 6 & 5 & 5 & 5 & 4 & 10 & 10 & 10 & 10 & 10 \\
\hline Site engineer 6 & 6 & 7 & 4 & 7 & 3 & 8 & 8 & 8 & 8 & 8 \\
\hline Site engineer 7 & 7 & 7 & 5 & 7 & 4 & 7 & 7 & 7 & 7 & 7 \\
\hline Site engineer 8 & 6 & 7 & 5 & 7 & 4 & 8 & 8 & 8 & 8 & 8 \\
\hline Site engineer 9 & 6 & 7 & 6 & 7 & 4 & 10 & 10 & 10 & 10 & 10 \\
\hline Site engineer 10 & 6 & 5 & 5 & 5 & 4 & 7 & 7 & 7 & 7 & 7 \\
\hline
\end{tabular}

Figure 11. The approximate durations of each activity based on site engineer experiences in similar projects.

\begin{tabular}{|c|c|c|c|c|c|c|c|c|c|}
\hline \multicolumn{2}{|r|}{ Activities } & \multirow{2}{*}{$\begin{array}{c}\begin{array}{c}\text { Number of } \\
\text { Engineers }\end{array} \\
5 \\
\end{array}$} & \multirow{2}{*}{\begin{tabular}{|c|} 
Duration \\
6 \\
\end{tabular}} & \multirow{2}{*}{\begin{tabular}{|c|} 
Probability \\
0.5 \\
\end{tabular}} & \multicolumn{2}{|r|}{ Activities } & \multirow{2}{*}{\begin{tabular}{|c|}
$\begin{array}{c}\text { Number of } \\
\text { Engineers }\end{array}$ \\
6 \\
\end{tabular}} & \multirow{2}{*}{\begin{tabular}{|c|} 
Duration \\
7
\end{tabular}} & \multirow{2}{*}{$\begin{array}{c}\text { Probability } \\
0.6\end{array}$} \\
\hline \multirow{3}{*}{1} & \multirow{3}{*}{$\begin{array}{c}\text { Excavation \& } \\
\text { levelling }\end{array}$} & & & & \multirow{3}{*}{7} & \multirow{3}{*}{$\begin{array}{c}\text { Beams \& Slab } \\
\text { GF }\end{array}$} & & & \\
\hline & & 3 & 7 & \begin{tabular}{|l|}
0.3 \\
\end{tabular} & & & 3 & 5 & 0.3 \\
\hline & & 2 & 4 & 0.2 & & & 1 & 10 & 0.1 \\
\hline \multirow{3}{*}{2} & \multirow{3}{*}{ PC Footing } & 6 & 3 & 0.6 & \multirow{3}{*}{8} & \multirow{3}{*}{ Columns First } & 7 & 7 & 0.7 \\
\hline & & 3 & 4 & 0.3 & & & 2 & 5 & 0.2 \\
\hline & & 1 & 2 & 0.1 & & & 1 & 8 & 0.1 \\
\hline \multirow{4}{*}{3} & \multirow{4}{*}{ RC Footing } & 5 & 7 & 0.5 & \multirow{3}{*}{9} & \multirow{3}{*}{$\begin{array}{c}\text { Beams \& Slab } \\
\text { First }\end{array}$} & 6 & 7 & 0.6 \\
\hline & & 2 & 8 & 0.2 & & & 3 & 5 & 0.3 \\
\hline & & 2 & 6 & 0.2 & & & 1 & 10 & 0.1 \\
\hline & & 1 & 10 & 0.1 & \multirow{3}{*}{10} & \multirow{3}{*}{ Columns Second } & 7 & 6 & 0.7 \\
\hline \multirow{3}{*}{4} & \multirow{3}{*}{ Columns GF } & 7 & 7 & 0.7 & & & 2 & 4 & 0.2 \\
\hline & & 2 & 5 & 0.2 & & & 1 & 7 & 0.1 \\
\hline & & 1 & 8 & 0.1 & \multirow{3}{*}{11} & \multirow{3}{*}{$\begin{array}{c}\text { Beams \& Slab } \\
\text { Second }\end{array}$} & 6 & 7 & 0.6 \\
\hline \multirow{3}{*}{5} & \multirow{3}{*}{ Backfilling } & 5 & 4 & 0.5 & & & 3 & 5 & 0.3 \\
\hline & & 3 & 3 & 0.3 & & & 1 & 10 & 0.1 \\
\hline & & 2 & 5 & 0.2 & \multirow{3}{*}{12} & \multirow{3}{*}{ Columns Third } & 7 & 6 & 0.7 \\
\hline \multirow{3}{*}{6} & \multirow{3}{*}{ S.O.G } & 6 & 4 & 0.6 & & & 2 & 4 & 0.2 \\
\hline & & 3 & 3 & 0.3 & & & 1 & 7 & 0.1 \\
\hline & & 1 & 2 & 0.1 & & & & & \\
\hline
\end{tabular}

Figure 12. Analysis of the survey results. 


\begin{tabular}{|c|c|c|c|c|c|c|c|c|c|}
\hline \multicolumn{2}{|r|}{ Activities } & \multirow{2}{*}{\begin{tabular}{|c|}
$\begin{array}{r}\text { Number of } \\
\text { Engineers }\end{array}$ \\
6 \\
\end{tabular}} & \multirow{2}{*}{\begin{tabular}{|c|} 
Duration \\
7
\end{tabular}} & \multirow{2}{*}{\begin{tabular}{|c|} 
Probability \\
0.6 \\
\end{tabular}} & \multicolumn{2}{|r|}{ Activities } & \multirow{2}{*}{\begin{tabular}{|c|}
$\begin{array}{c}\text { Number of } \\
\text { Engineers }\end{array}$ \\
5 \\
\end{tabular}} & \multirow{2}{*}{\begin{tabular}{|c|} 
Duration \\
8 \\
\end{tabular}} & \multirow{2}{*}{\begin{tabular}{|c|} 
Probability \\
0.5 \\
\end{tabular}} \\
\hline \multirow{3}{*}{13} & \multirow{3}{*}{$\begin{array}{c}\text { Beams \& Slabs } \\
\text { Third }\end{array}$} & & & & \multirow{3}{*}{19} & \multirow{3}{*}{$\begin{array}{l}\text { Brickworks } \\
\text { Second }\end{array}$} & & & \\
\hline & & 3 & 5 & 0.3 & & & 3 & 7 & 0.3 \\
\hline & & 1 & 10 & 0.1 & & & 2 & 10 & 0.2 \\
\hline \multirow{3}{*}{14} & \multirow{3}{*}{ Columns Fourth } & 7 & 5 & 0.7 & \multirow{3}{*}{20} & \multirow{3}{*}{ Brickworks Third } & 5 & 8 & 0.5 \\
\hline & & 2 & 4 & 0.2 & & & 3 & 7 & 0.3 \\
\hline & & 1 & 6 & 0.1 & & & 2 & 10 & 0.2 \\
\hline \multirow{3}{*}{15} & \multirow{3}{*}{$\begin{array}{l}\text { Beams \& Slabs } \\
\text { Fourth }\end{array}$} & 6 & 7 & 0.6 & \multirow{3}{*}{21} & \multirow{3}{*}{$\begin{array}{l}\text { Brickworks } \\
\text { Fourth }\end{array}$} & 5 & 8 & 0.5 \\
\hline & & 3 & 5 & 0.3 & & & 3 & 7 & 0.3 \\
\hline & & 1 & 10 & 0.1 & & & 2 & 10 & 0.2 \\
\hline \multirow{3}{*}{16} & \multirow{3}{*}{$\begin{array}{c}\text { Columns \& Parapet } \\
\text { Roof }\end{array}$} & 7 & 4 & 0.7 & & & 1 & & \\
\hline & & 2 & 3 & 0.2 & & & & & \\
\hline & & 1 & 5 & 0.1 & & & & & \\
\hline \multirow{3}{*}{17} & \multirow{3}{*}{ Brickworks Ground } & 5 & 8 & 0.5 & & & & & \\
\hline & & 3 & 7 & 0.3 & & & & & \\
\hline & & 2 & 10 & 0.2 & \multirow{4}{*}{\multicolumn{4}{|c|}{ Number of engineers / 10}} & \\
\hline \multirow{3}{*}{18} & \multirow{3}{*}{ Brickworks First } & 5 & 8 & 0.5 & & & & & \\
\hline & & 3 & 7 & 0.3 & & & & & \\
\hline & & 2 & 10 & 0.2 & & & & & \\
\hline
\end{tabular}

Figure 13. Analysis of the survey results.

Updates took place periodically; actual durations were assigned to the "updates sheets", to have the earned duration metrics calculated automatically. The duration estimation index (DEI) for the finished activities until the cutoff date was calculated. The activities whose durations were calculated with accuracies under specified levels were highlighted with certain colors. This made it clear for the decision makers that some activities had estimation errors due to certain factors. Some of these factors may have been the production rates of the resources allocated for these activities or the productivity rates used to estimate the durations of these activities. The duration performance index (DPI) for the activities in progress to the cutoff date was calculated, highlighting the activities with DPI under certain levels with different colors. These activities were risky and subject to delay due to low performances indicated by the DPI value. An example of the activities highlighted according to certain criteria are shown in Figures 14 and 15.

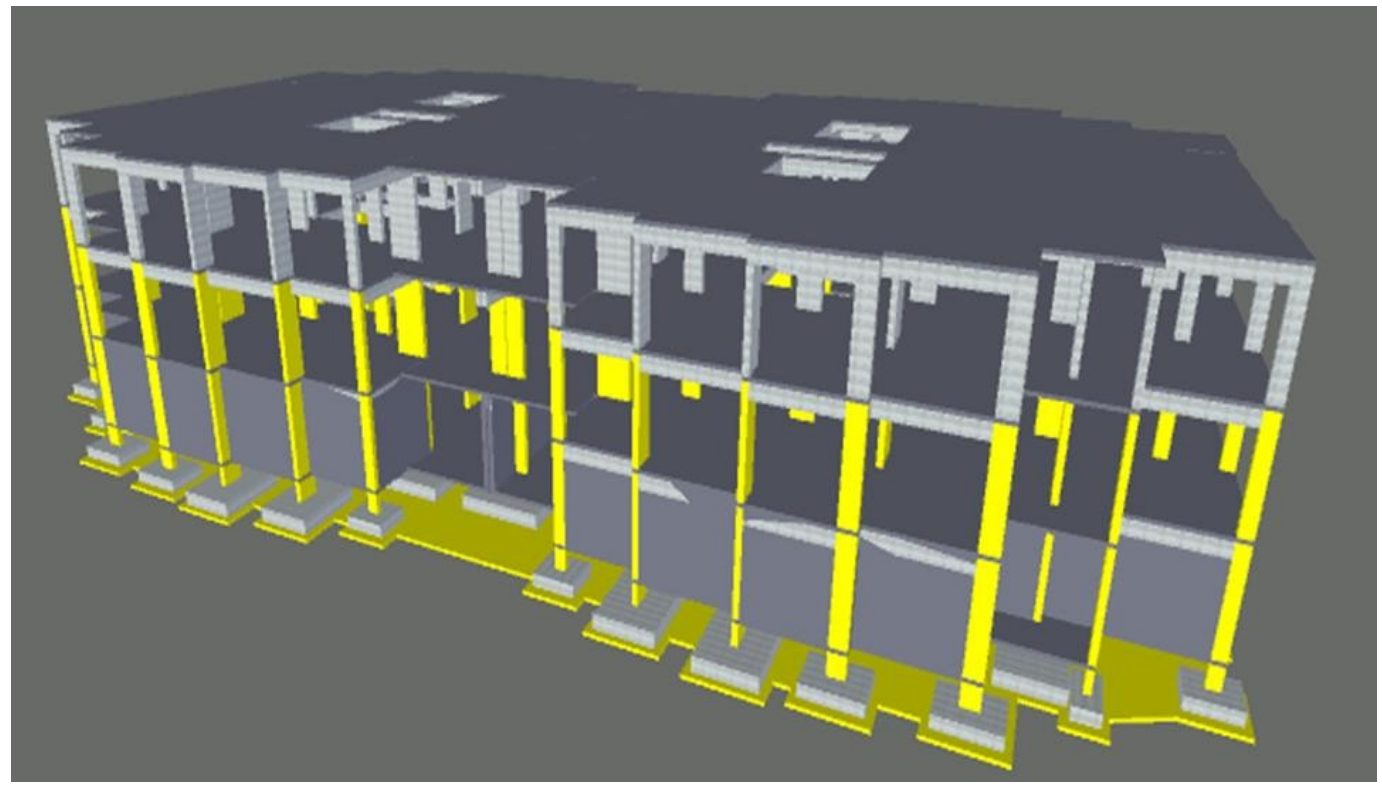

Figure 14. Activities with a DEI of less than 0.80 appeared in yellow during the simulation. 


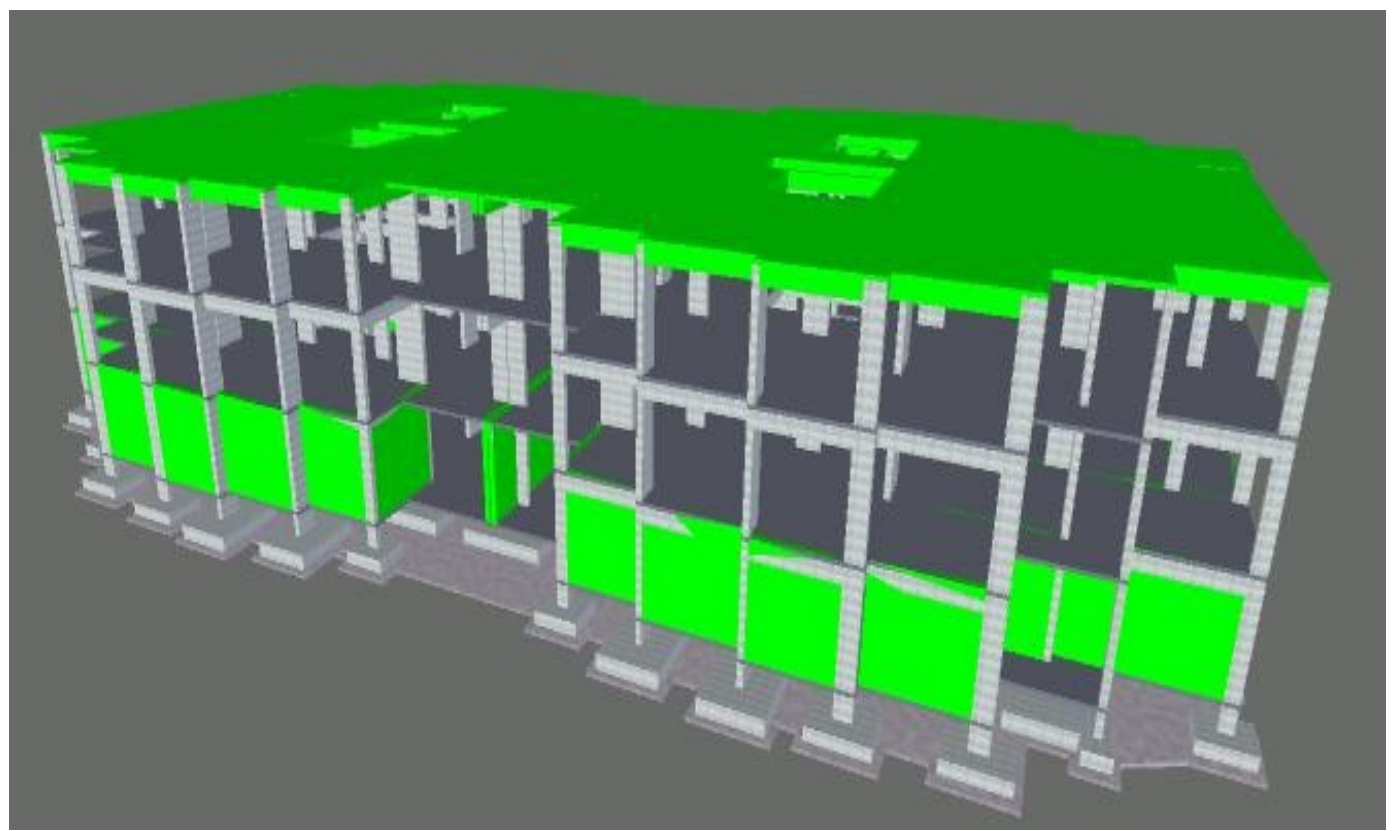

Figure 15. Activities with a DPI of less than 0.80 appeared in green during the simulation.

The critical path changed with each update after replacing the baseline durations of the finished activities in each update with the actual ones. The new critical activities were highlighted automatically in the spreadsheet model. Subsequently, the highlighted activities appeared on the $4 \mathrm{D}$ building model during the simulation to act as a warning tool for the contractor to avoid future delays, as shown in Figure 16.

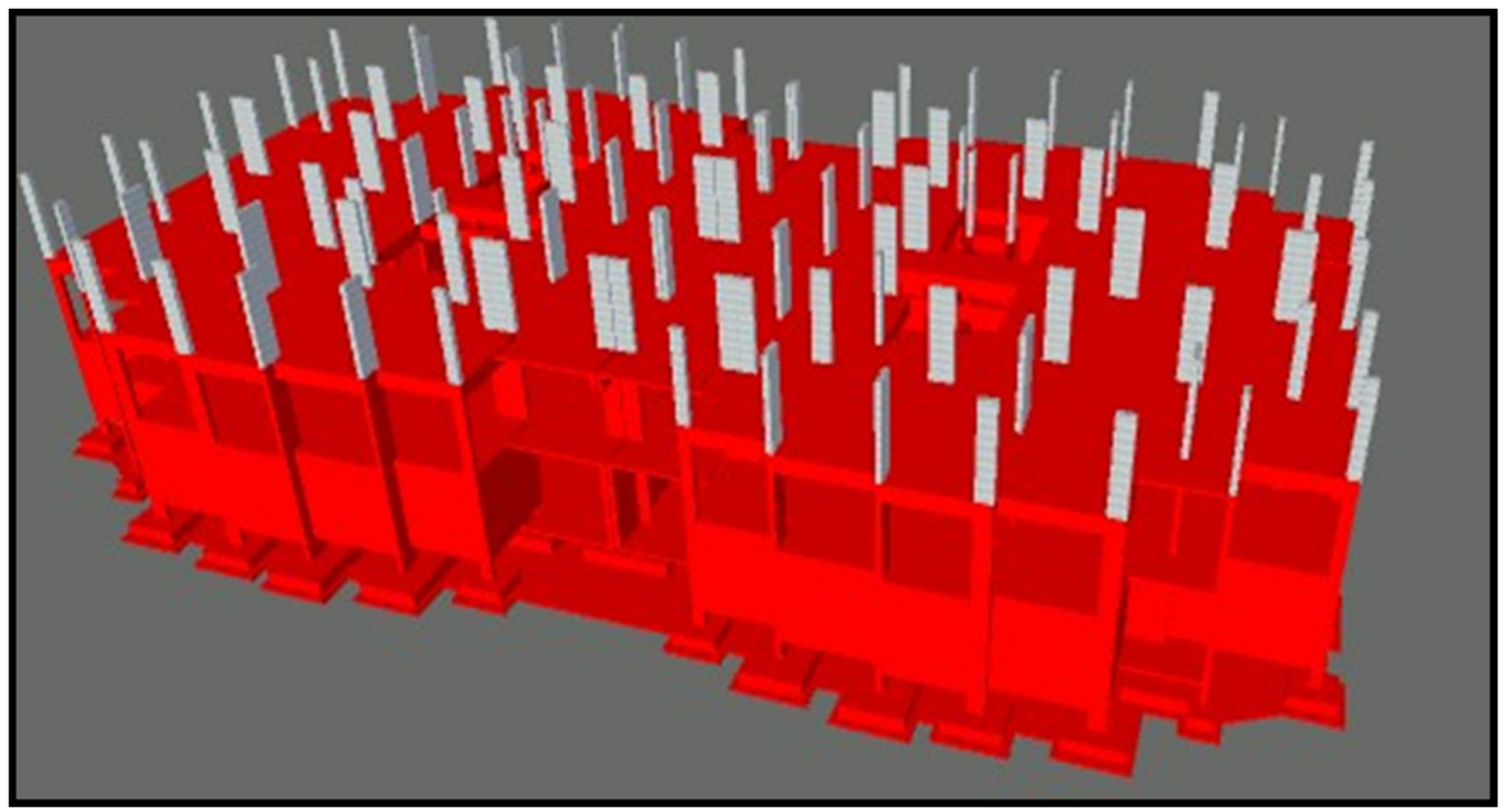

Figure 16. Critical activities appeared in red during the simulation.

\section{Validation of the Proposed Decision Support System}

The process of validation went through two major steps: (1) the probabilities assigned to the durations of each activity in the baseline scenario were similar to reality. They were based on a questionnaire conducted, geared toward ten site engineers. The results of this questionnaire were organized and analyzed, as shown in Table 2. (2) Through getting feedback from construction practitioners. 
Table 2. Activity durations with their probabilities.

\begin{tabular}{|c|c|c|c|c|}
\hline & Activities & $\begin{array}{l}\text { Number of } \\
\text { Engineers }\end{array}$ & Duration & Probability \\
\hline \multirow{3}{*}{1} & \multirow{3}{*}{ Excavation and leveling } & 5 & 6 & 0.5 \\
\hline & & 3 & 7 & 0.3 \\
\hline & & 2 & 4 & 0.2 \\
\hline \multirow{3}{*}{2} & \multirow{3}{*}{ PC footing } & 6 & 3 & 0.6 \\
\hline & & 3 & 4 & 0.3 \\
\hline & & 1 & 2 & 0.1 \\
\hline \multirow{4}{*}{3} & \multirow{4}{*}{$\mathrm{RC}$ footing } & 5 & 7 & 0.5 \\
\hline & & 2 & 8 & 0.2 \\
\hline & & 2 & 6 & 0.2 \\
\hline & & 1 & 10 & 0.1 \\
\hline \multirow{3}{*}{4} & \multirow{3}{*}{ Columns (ground floor) } & 7 & 7 & 0.7 \\
\hline & & 2 & 5 & 0.2 \\
\hline & & 1 & 8 & 0.1 \\
\hline \multirow{3}{*}{5} & \multirow{3}{*}{ Backfilling } & 5 & 4 & 0.5 \\
\hline & & 3 & 3 & 0.3 \\
\hline & & 2 & 5 & 0.2 \\
\hline \multirow{3}{*}{6} & \multirow{3}{*}{ Slab on grade } & 6 & 4 & 0.6 \\
\hline & & 3 & 3 & 0.3 \\
\hline & & 1 & 2 & 0.1 \\
\hline \multirow{3}{*}{7} & \multirow{3}{*}{ Beams and slab GF } & 6 & 7 & 0.6 \\
\hline & & 3 & 5 & 0.3 \\
\hline & & 1 & 10 & 0.1 \\
\hline \multirow{3}{*}{8} & \multirow{3}{*}{ Columns first } & 7 & 7 & 0.7 \\
\hline & & 2 & 5 & 0.2 \\
\hline & & 1 & 8 & 0.1 \\
\hline \multirow{3}{*}{9} & \multirow{3}{*}{ Beams and slab first } & 6 & 7 & 0.6 \\
\hline & & 3 & 5 & 0.3 \\
\hline & & 1 & 10 & 0.1 \\
\hline \multirow{3}{*}{10} & \multirow{3}{*}{ Columns second } & 7 & 6 & 0.7 \\
\hline & & 2 & 4 & 0.2 \\
\hline & & 1 & 7 & 0.1 \\
\hline \multirow{3}{*}{11} & \multirow{3}{*}{ Beams and slab second } & 6 & 7 & 0.6 \\
\hline & & 3 & 5 & 0.3 \\
\hline & & 1 & 10 & 0.1 \\
\hline \multirow{3}{*}{12} & \multirow{3}{*}{ Columns third } & 7 & 6 & 0.7 \\
\hline & & 2 & 4 & 0.2 \\
\hline & & 1 & 7 & 0.1 \\
\hline \multirow{3}{*}{13} & \multirow{3}{*}{ Beams and slabs third } & 6 & 7 & 0.6 \\
\hline & & 3 & 5 & 0.3 \\
\hline & & 1 & 10 & 0.1 \\
\hline
\end{tabular}


Table 2. Cont.

\begin{tabular}{|c|c|c|c|c|}
\hline & Activities & $\begin{array}{l}\text { Number of } \\
\text { Engineers }\end{array}$ & Duration & Probability \\
\hline \multirow{3}{*}{14} & \multirow{3}{*}{ Columns fourth } & 7 & 5 & 0.7 \\
\hline & & 2 & 4 & 0.2 \\
\hline & & 1 & 6 & 0.1 \\
\hline \multirow{3}{*}{15} & \multirow{3}{*}{ Beams and slabs fourth } & 6 & 7 & 0.6 \\
\hline & & 3 & 5 & 0.3 \\
\hline & & 1 & 10 & 0.1 \\
\hline \multirow{3}{*}{16} & \multirow{3}{*}{ Columns and parapet roof } & 7 & 4 & 0.7 \\
\hline & & 2 & 3 & 0.2 \\
\hline & & 1 & 5 & 0.1 \\
\hline \multirow{3}{*}{17} & \multirow{3}{*}{ Brickworks ground } & 5 & 8 & 0.5 \\
\hline & & 3 & 7 & 0.3 \\
\hline & & 2 & 10 & 0.2 \\
\hline \multirow{3}{*}{18} & \multirow{3}{*}{ Brickworks first } & 5 & 8 & 0.5 \\
\hline & & 3 & 7 & 0.3 \\
\hline & & 2 & 10 & 0.2 \\
\hline \multirow{3}{*}{19} & \multirow{3}{*}{ Brickworks second } & 5 & 8 & 0.5 \\
\hline & & 3 & 7 & 0.3 \\
\hline & & 2 & 10 & 0.2 \\
\hline \multirow{3}{*}{20} & \multirow{3}{*}{ Brickworks third } & 5 & 8 & 0.5 \\
\hline & & 3 & 7 & 0.3 \\
\hline & & 2 & 10 & 0.2 \\
\hline \multirow{3}{*}{21} & \multirow{3}{*}{ Brickworks fourth } & 5 & 8 & 0.5 \\
\hline & & 3 & 7 & 0.3 \\
\hline & & 2 & 10 & 0.2 \\
\hline
\end{tabular}

The proposed system was explained to five site engineers in different companies to be applied on their own projects, which were similar in type to the applied project. According to those engineers, it proved a significant level of performance in the tracking and monitoring of the construction projects. It acted as a helpful tool for all construction parties, as the consultants and decision makers exploited the results visualized to judge the contractor's performance and adherence to the schedule. Moreover, the owners of these projects were able to track the progress of their projects visually without going too deeply into complex technical issues.

\section{Final Remarks and Conclusions}

The combination of EDM and BIM used for monitoring the duration performance of building projects is one of the study's primary contributions. EDM factors were used to monitor the performance of a real-life small residential project execution. This was utilized to visually detect activities running with performances of less than $80 \%$ or, in other words, activities with a DPI below 0.80 , to make it clear that there were errors in the calculation of the durations for some activities. Analyses were carried out over several periods to track the project's performance at various stages during the construction process. Furthermore, to evaluate the results of the proposed decision support system (DSS), a comparison with the actual project data was conducted. The results were nearly similar to 
the actual results collected from the site during construction, which proved the reliability of the proposed system.

The imaginary project executions were generated using Monte Carlo simulations. Accordingly, the output was utilized to derive the realistic probability distribution for the total project duration. At each update phase, after replacing the baseline durations of the finished activities with the actual ones, the durations required to meet the contract duration (95 days) were extracted from the simulation. They were similar to what was actually employed during construction, based on the site engineer's experience. This proves the reliability of the proposed system and how close the output is to reality.

Despite the limited and small-scale project simulation, the proposed system was shown to be a viable tool for tracking and monitoring project schedules. This study shows the significance of building information modeling (BIM) tools in the process of construction project time control. Moreover, this study makes it clear that the earned duration management system is the most effective project time control technique. It leads to accurate results that any project manager can rely on.

The intense focus on project duration accomplishment could be considered a potential restriction in terms of the level of evaluation offered to the project team, in addition to the inconsistency of the duration and cost performance. Further improvements for the proposed system can be made to monitor the project costs and duration, at the same time, by employing EDM. This could be another future research topic in this area. Another limitation involves the limited scope of this study, based on the type and scale of the project employed. Upon further adjustments and improvements for the proposed system, it could be applied, in the future, to a larger scale construction project, different in the type and manner from residential buildings.

The link between the Navisworks model (BIM technology) and the spreadsheet model (containing the formulas for the EDM technique) could be another future research topic. A more sophisticated and developed method could be used in the future to combine EDM metrics with BIM technology.

The developed system could be applied other project environments. It could be practically implemented in real-life residential projects within different project delivery systems. The authors believe that this work will assist academic researchers and project and construction management practitioners. Even though EDM is a relatively new project control technique in project and construction management literature, the building information modeling tools and Monte Carlo simulation principles employed in the proposed system are frequently used. These principles were utilized in controlling construction projects and are well recognized by project management specialists.

Author Contributions: Conceptualization, A.A., S.Y.M., H.M.A.; methodology, A.A., S.Y.M., H.M.A.; validation, H.M.A.; software, H.M.A.; visualization, H.M.A.; writing-original draft preparation, A.A., S.Y.M., H.M.A.; writing—review and editing, A.A., S.Y.M., H.M.A.; supervision, A.A., S.Y.M.; project administration, A.A., S.Y.M., H.M.A. All authors have read and agreed to the published version of the manuscript.

Funding: This research received no external funding.

Data Availability Statement: Some or all data, models, or code generated or used during the study are proprietary or confidential in nature and may only be provided with restrictions.

Conflicts of Interest: The authors declare no conflict of interest.

\section{References}

1. Assaf, S.A.; Al-Hejji, S. Causes of delay in large construction projects. Int. J. Proj. Manag. 2006, 24, 349-357. [CrossRef]

2. Sambasivan, M.; Soon, Y.W. Causes and effects of delays in Malaysian construction industry. Int. J. Proj. Manag. 2007, 25, 517-526. [CrossRef]

3. Wanjari, S.P.; Dobariya, G. Identifying factors Causing cost overrun of the construction projects in India. Sādhanā 2016, 41, 679-693. [CrossRef] 
4. Acebes, F.; Pajares, J.; López-Paredes, A. Statistical Learning Techniques for Project Control. In Project Management and Engineering Research. Lecture Notes in Management and Industrial Engineering; Muñoz, A.J.L., Blanco, Y.J.L., Capuz-Rizo, S.F., Eds.; Springer: Cham, Switzerland, 2021. [CrossRef]

5. Christensen, D.S. The Role of Analysis in C/SCSC. Program Manag. Mag. 1990, 3, 26-33. Available online: https://citeseerx.ist. psu.edu/viewdoc/download?doi=10.1.1.1085.1864\&rep=rep1\&type=pdf (accessed on 18 January 2021).

6. Fleming, Q.W.; Koppelman, J.M. Implementing earned-value project management in ten easy steps. In Field Guide to Project Management; John Wiley \& Sons, Inc.: Hoboken, NJ, USA, 2004; pp. 521-539. [CrossRef]

7. A Guide to the Project Management Body of Knowledge: (Pmbok Guide); PMI-Project Management Inst.: Newtown Square, PA, USA, 2008.

8. Lipke, W. Schedule is different. Meas. News 2003, 31, 31-34.

9. Anbari, F.T. Earned value project management method and extensions. Proj. Manag. J. 2003, 34, 12-23. [CrossRef]

10. Elshaer, R. Impact of sensitivity information on the prediction of project's duration using earned schedule method. Int. J. Proj. Manag. 2013, 31, 579-588. [CrossRef]

11. Vandevoorde, S.; Vanhoucke, M. A comparison of different project duration forecasting methods using earned value metrics. Int. J. Proj. Manag. 2006, 24, 289-302. [CrossRef]

12. Andrade, P.A.; Martens, A.; Vanhoucke, M. Using real project schedule data to compare earned schedule and earned duration management project time forecasting capabilities. Autom. Constr. 2019, 99, 68-78. [CrossRef]

13. Bejarano, E. Integration of earn value management into Bim projects. J. Archit. Eng. Technol. 2019, 8, 2. [CrossRef]

14. Balali, A.; Valipour, A.; Antucheviciene, J.; Šaparauskas, J. Improving the Results of the Earned Value Management Technique Using Artificial Neural Networks in Construction Projects. Symmetry 2020, 12, 1745. [CrossRef]

15. Dillibabu, R.; Krishnaiah, K. Cost estimation of a software product using COCOMO II.2000 model—A case study. Int. J. Proj. Manag. 2005, 23, 297-307. [CrossRef]

16. Jacob, D.S.; Kane, M. Forecasting schedule completion using earned value metrics revisited. Meas. News $2004,1,7$.

17. Barraza, G.A.; Back, W.E.; Mata, F. Probabilistic forecasting of project performance using stochastic s curves. J. Constr. Eng. Manag. 2004, 130, 25-32. [CrossRef]

18. Salari, M.; Yousefi, N.; Asgary, M.M. Cost performance estimation in construction projects using fuzzy time series. In Project Management: Concepts, Methodologies, Tools, and Applications; IGI Global: Hershey, PA, USA, 2016; pp. 359-370. [CrossRef]

19. Lipke, W.; Zwikael, O.; Henderson, K.; Anbari, F. Prediction of project outcome. Int. J. Proj. Manag. 2009, 27, 400-407. [CrossRef]

20. Lipke, W. Project duration forecasting: A Comparison of Earned Value Management Methods to Earned Schedule. Meas. News 2009, 2, 24-31.

21. Turner, R.J.; Huemann, M.; Anbari, F.T.; Bredillet, C.N. Perspectives on Projects; Routledge: London, UK, 2010. [CrossRef]

22. Votto, R.; Lee Ho, L.; Berssaneti, F. Applying and assessing performance of Earned Duration management Control charts for EPC project duration. J. Constr. Eng. Manag. 2020, 146, 04020001. [CrossRef]

23. Vanhoucke, M. Using activity sensitivity and network topology information to monitor project time performance. Omega 2010, 38, 359-370. [CrossRef]

24. Vanhoucke, M. On the dynamic use of project performance and schedule risk information during project tracking. Omega 2011, 39, 416-426. [CrossRef]

25. Colin, J.; Vanhoucke, M. A comparison of the performance of various project control methods using earned value management systems. Expert Syst. Appl. 2015, 42, 3159-3175. [CrossRef]

26. Khamooshi, H.; Golafshani, H. EDM: Earned DURATION management, a new approach to schedule performance management and measurement. Int. J. Proj. Manag. 2014, 32, 1019-1041. [CrossRef]

27. Vanhoucke, M.; Andrade, P.; Salvaterra, F.; Batselier, J. Introduction to earned duration. Meas. News 2015, 2, 15-27.

28. Koo, B.; Fischer, M. Feasibility study of $4 \mathrm{~d}$ cad in commercial construction. J. Constr. Eng. Manag. 2000, 126, 251-260. [CrossRef]

29. Crowther, J.; Ajayi, S.O. Impacts of 4D BIM on construction project performance. Int. J. Constr. Manag. 2021, 21, 724-737. [CrossRef]

30. Kummel, W. Building Information Modeling: Planning and Managing Construction Projects with 4D CAD and Simulations (McGraw-Hill Construction Series); McGraw-Hill Education: New York, NY, USA, 2008.

31. Peterson, F.; Hartmann, T.; Fruchter, R.; Fischer, M. Teaching construction project management with BIM SUPPORT: Experience and lessons learned. Autom. Constr. 2011, 20, 115-125. [CrossRef]

32. Arboleda, A.M.; Rivera, V.D.F. Implementation of BIM Methodologies as a Tool for Planning and Controlling the Construction Process of a Building in Bogotá. 2012. Available online: https:/ / repository.javeriana.edu.co/handle/10554/11135 (accessed on 18 January 2021).

33. Ahmed, S.M.; Emam, H.H.; Farrell, P.E.T.E.R. Barriers to BIM/4D implementation in Qatar. Smart Sustain. Healthy Cities 2014, 535.

34. Moon, H.; Dawood, N.; Kang, L. Development of workspace conflict visualization system using 4d object of work schedule. Adv. Eng. Inform. 2014, 28, 50-65. [CrossRef]

35. Boton, C.; Halin, G.; Kubicki, S.; Forgues, D. Challenges of big data in the age of building Information Modeling: A high-level Conceptual Pipeline. In Lecture Notes in Computer Science; Springer: Singapore, 2015; pp. 48-56. [CrossRef] 